\title{
‡USGS
}

science for a changing world

In cooperation with U.S. Agency for International Development

\section{Calibrated Landsat ETM+ Nonthermal-Band Image Mosaics of Afghanistan}

By Philip A. Davis

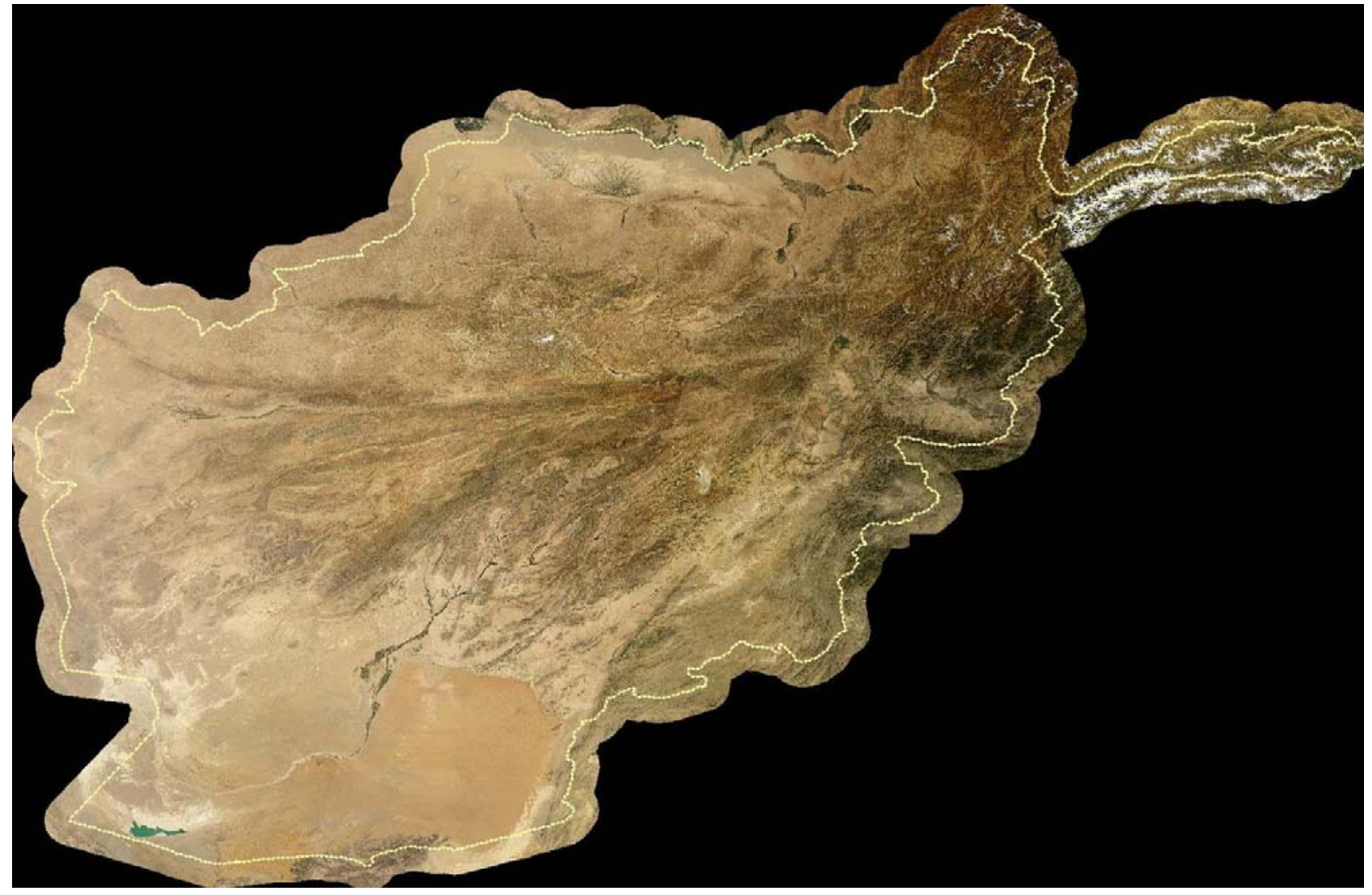

Open-File Report 2006-1345

U.S. Department of the Interior

U.S. Geological Survey 


\title{
U.S. Department of the Interior DIRK KEMPTHORNE, Secretary
}

\section{U.S. Geological Survey \\ Mark D. Myers, Director}

\author{
U.S. Geological Survey, Reston, Virginia 20192 \\ 2006
}

For product and ordering information:

World Wide Web: http://www.usgs.gov/pubprod

Telephone: 1-888-ASK-USGS

For more information on the USGS - the Federal source for science about the Earth, its natural and living resources, natural hazards, and the environment:

World Wide Web: http://www.usgs.gov

Telephone: 1-888-ASK-USGS

Suggested citation:

Davis, P. A., 2006, Calibrated Landsat ETM+ nonthermal-band image mosaics of Afghanistan, U.S. Geological Survey Open-File Report 2006-1345, 18 p. [http://pubs.usgs.gov/of2006/1345/ ].

Any use of trade, product, or firm names is for descriptive purposes only and does not imply endorsement by the U.S. Government.

Although this report is in the public domain, permission must be secured from the individual copyright owners to reproduce any copyrighted material contained within this report. 


\section{Contents}

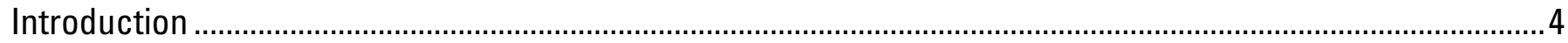

Characteristics of Landsat ETM+ Satellite Image Data ..................................................................................

Processing of Landsat ETM+ Satellite Image Data...........................................................................................

Conversion of Raw Satellite Data to Relative Reflectance ...........................................................................

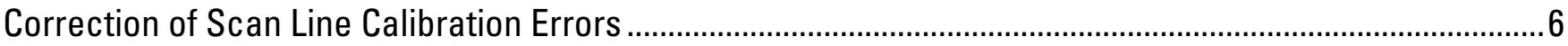

Countrywide Image-to-Image Reflectance Calibration....................................................................................

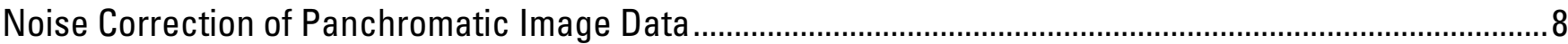

Resoultion Enhancement of the 28.5-m Reflectance Image Data ...............................................................

Reprojection of Landsat Scenes along UTM Zone Borders .......................................................................

Mosaicking of Landsat Scenes into Map Quadrangles ............................................................................

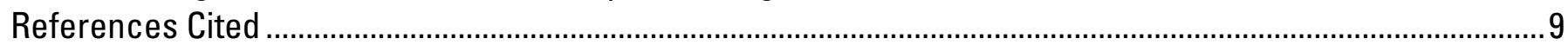

\section{Figures}

1. Landsat ETM+ scene outlines superposed on a map of Afghanistan. "P" indicates Path (red) and "R" indicates Row (blue).

2. Panchromatic image of an agricultural area in southern Afghanistan showing (a) dense, random noise present in the original orthorectified Landsat panchromatic images obtained from the EROS Data Center archive, and (b) the corresponding image after application of the adaptive sigma filter and an edge enhancement filter

3. Landsat false-color image at (a) original 28.5-m resolution and (b) enhanced $14.25-\mathrm{m}$ resolution.

Landsat bands 7, 4, and 1 are displayed as red, green, and blue, respectively...

4. Map tile scheme for the Afghanistan project with each $1^{\circ} \times 2^{\circ}$ map quadrangle designated by its lower left corner latitude and longitude.

\section{Tables}

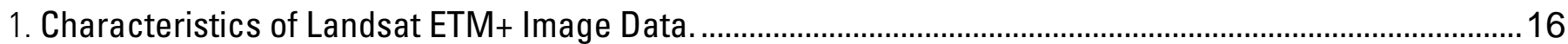

2. Landsat ETM+ Image Data Used in the Countrywide Image Mosaic.............................................................17 


\title{
Calibrated Landsat ETM+ Nonthermal-Band Image Mosaics of Afghanistan
}

\author{
By Philip A. Davis'
}

\section{Introduction}

In 2005, the U.S. Agency for International Development and the U.S. Trade and Development Agency contracted with the U.S. Geological Survey to perform assessments of the natural resources within Afghanistan. The assessments concentrate on the resources that are related to the economic development of that country. Therefore, assessments were initiated in oil and gas, coal, mineral resources, water resources, and earthquake hazards. All of these assessments require geologic, structural, and topographic information throughout the country at a finer scale and better accuracy than that provided by the existing maps, which were published in the 1970's by the Russians and Germans. The very rugged terrain in Afghanistan, the large scale of these assessments, and the terrorist threat in Afghanistan indicated that the best approach to provide the preliminary assessments was to use remotely sensed, satellite image data, although this may also apply to subsequent phases of the assessments. Therefore, the first step in the assessment process was to produce satellite image mosaics of Afghanistan that would be useful for these assessments. This report discusses the production and characteristics of the fundamental satellite image databases produced for these assessments, which are calibrated image mosaics of all six Landsat nonthermal (reflected) bands.

\section{Characteristics of Landsat ETM+ Satellite Image Data}

Landsat Enhanced Thematic Mapper Plus (ETM+) data were used to construct the image mosaics of Afghanistan. These data consist of six reflected (nonthermal) bands at 28.5-m spatial resolution, two thermal infrared bands at 57.0-m spatial resolution, and a panchromatic band at 14.25-m spatial resolution. The wavelength range for each of these bands is listed in Table 1. The thermal infrared bands include a high- and low-gain image, but these two broad wavelength thermal images are not generally useful for geologic applications and were therefore not included in our image mosaics. The wavelength band of the panchromatic image covers most of the visible wavelength region (Table 1). Although not useful for mapping surface material, due to its broad wavelength range, its higher spatial resolution provides more detailed morphologic information than the other lower-resolution reflected wavelength band images.

All of the Landsat scenes used to build the image mosaics are listed in Table 2. The scene ID for each Landsat ETM+ image listed in Table 2 (e.g., ELP149R034_7T20010930) provides the Path ("P") and Row ("R") of the satellite during image acquisition, the "7T" indicates that the

\footnotetext{
${ }^{1}$ U.S. Geological Survey, 2255 North Gemini Drive, Flagstaff, AZ 86001
} 
scene is Landsat 7 Thematic Mapper, and the "20010930" indicates the date of acquisition, which is September 30, 2001 in this example. Figure 1 shows the Landsat ETM+ Path and Row grid for Afghanistan. These scenes were selected from NASA's Landsat Orthorectified ETM+ Imagery Archive that resides at the EROS Data Center in South Dakota. Landsat scenes within that archive meet NASA's criteria for orthorectification, which included acquisition date, cloud percentage, data quality, and best available phenology (Kalluri et al., 2000). The raw Landsat images were orthorectified by Earth Satellite Corporation to a positional accuracy of 50 meters. The image data are provided in Universal Transverse Mercator (UTM) map projection using the WGS84 datum. Afghanistan has three UTM zones (41, 42, and 43); zone 42 lies between $66^{\circ}$ and $72^{\circ}$ East longitude. We performed an additional selection process on the NASA archive because there are replicate image acquisitions for some scenes. Our selection process attempted to choose scenes that were acquired (1) within the same year to avoid surface changes between scenes, (2) near summer solstice to provide high solar elevation angles and minimize mountain shadows, and (3) with minimal cloud and snow/ice cover because most of our resource assessments (except water resources) need to see the rock and soil surfaces. Most of the scenes used in the mosaic were acquired in 2001, some in 2000, and only two in 1999.

Although there are more sophisticated satellites now in Earth's orbit (e.g., ASTER, HYPERION), Landsat ETM+ provides a larger field of view (about 32,400 $\mathrm{km}^{2}$ per scene) and spectral distinction among major rock, soil, and vegetation types. For example, Landsat ETM+ bands 1,2, and 3 cover the blue, green, and red wavelength regions of the visible spectrum and can be used to make a natural color image of the surface. Iron oxides, consisting of ferric $\left(\mathrm{Fe}^{+3}\right)$ and ferrous $\left(\mathrm{Fe}^{+2}\right)$ iron, absorb in these visible wavelength regions and within the near-infrared band 4 (due to intervalence charge transfer and crystal field transitions) and, therefore, ratios of these bands can indicate relative amounts of surface iron oxide (Hunt and Salisbury, 1970; Hunt et al., 1971a). Landsat ETM+ band 4 occurs in the near-infrared (NIR) wavelength region in which vegetation has the highest spectral reflectance because chlorophyll absorbs in most of the other Landsat ETM+ band wavelengths. Thus, the band ratio $4 / 3$ or the Normalized Difference Vegetation Index [NDVI $=(4-3) /(4+3)]$ is normally used to indicate the presence and health of surface vegetation. Landsat ETM+ bands 5 and 7 occur within the shortwave infrared region where absorptions occur due to molecular vibrations. Water bound in certain minerals (e.g., clays) experience $\mathrm{H}-\mathrm{O}-\mathrm{H}$ dipolar stretching and $\mathrm{OH}^{-}$bending, whose overtones and combination tones cause absorptions within band 5 and band 7 (Hunt and Salisbury, 1970). Surface materials containing $\mathrm{CO}^{-}$(carbonates) and $\mathrm{SO}^{=}$(sulfates) cause absorptions within band 7 due to lattice vibrations (Hunt and Salisbury, 1971; Hunt et al., 1971b). Thus, the shortwave infrared bands are very useful for mapping certain minerals and rock types containing those mineral groups. However, there are a number of different mineral groups that produce absorptions within the same ETM+ band and, therefore, the broad shortwave-infrared bands do not provide unambiguous identification of surface mineralogy or rock type.

\section{Processing of Landsat ETM+ Satellite Image Data}

Several steps were required to transform the raw 8-bit (numbers 0-255) Landsat ETM+ band data into relative reflectance data that is consistent image to image throughout the large area of Afghanistan. In each step every effort was made to retain the integrity of the original data to allow accurate, wide-area mapping for a variety of natural resources. The different steps consisted of (1) conversion of stored 8-bit data to relative reflectance data; (2) correction for any image errors (calibration errors in specific image scan lines); (4) image-to-image adjustment of reflectance 
values to obtain consistent data throughout the country; (5) noise reduction of the panchromatic image data; (6) resolution enhancement of the $28.5-\mathrm{m}$ band data to produce $14.25-\mathrm{m}$ band data; (7) reprojection of images along UTM zone boundaries; and (8) mosaicking scenes into our designated $1^{\circ}$ latitude $\mathrm{x} 2^{\circ}$ longitude map quadrangles.

\section{Conversion of Raw Satellite Data to Relative Reflectance}

During satellite image acquisition, the radiance $\left(\mathrm{mW} / \mathrm{cm}^{2} \bullet\right.$ sterdian $\left.\bullet \mu \mathrm{m}\right)$ observed by each Landsat band's charged coupled device (CCD) is converted to an 8-bit number (0-255) for efficient storage using each band's unique gain and bias values. The gain and bias for each CCD optimizes stored spectral sensitivity without saturation. The sensitivity of the stored 8-bit values is between $0.13 \%$ and $0.29 \%$ reflectance.

The atmosphere scatters a fraction of the solar incidence flux back to the satellite detectors before interacting with the Earth's surface. This scattering can be Rayleigh, which involves atmospheric water molecules, or Mie, which involves aerosols. The fraction of solar incidence flux scattered by the atmosphere increases from the near-infrared wavelength (Landsat band 4) to the blue wavelength (Landsat band 1) in a $1 / \lambda^{\mathrm{n}}$ relation, where $n$ can range from 4.0 for pure Rayleigh scattering to 1.0 for Mie scattering. Thus, the amount of scattering within the near-infrared band is very small compared to that within the blue band. This scattering has to be removed from ETM+ bands 1 through 4 in order to (1) produce consistent reflectance scene to scene, (2) allow the use of band ratios in mapping surface materials, and (3) produce reflectance spectra of surface materials that can be directly compared to laboratory spectral libraries of minerals, rocks, and vegetation.

The FLAASH (Fast Line-of-sight Atmospheric Analysis of Spectral Hypercubes) algorithm within ENVI image processing software was used to convert the stored 8-bit band values to their radiance values and then to remove the atmosphere and its scattering effects from the Landsat band images (RSI, 2004). This algorithm has been tested and shown to be accurate by Matthew et al. (2003). FLAASH incorporates the MODTRAN4 radiation transfer code and corrects for adjacency effects, which is ground-to-ground scattering of surface-reflected radiance that results in picture element (pixel) spectral mixing. Estimates of the water vapor column and the aerosol amount within each scene were obtained from periodic MODIS data; these data were supplied to FLAASH to produce a final corrected reflectance image for each Landsat band. The reflectance data produced by the FLAASH algorithm are multiplied by 10,000 and converted to 16-bit values to conserve disk space. However, the 16-bit files are still very large for creating a countrywide mosaic, especially at our preferred $14.25-\mathrm{m}$ resolution. Therefore, the band reflectance values were converted to 8 -bit values by multiplying their 16 -bit values by $(255 / 10,000)$. This conversion reduces the spectral sensitivity from $0.13 \%$ reflectance to $0.39 \%$ reflectance; the mountain shaded and snow/ice surfaces did not allow a less constrained 8-bit conversion. The calibrated 16-bit scenes are preserved for more detailed assessment requirements and are stored on our internal website (http://gisdata.usgs.net/website/afghan).

\section{Correction of Scan Line Calibration Errors}

Two of the 54 selected Landsat scenes had a few scan lines with anomalously high or low reflectance values in some of the bands. Replacement scenes without this problem had even larger problems associated with low sun angle, clouds, or snow cover. Therefore, a least squares method was devised to correct the few anomalous scan lines. Fortunately, the anomalous scan lines were not coincident in the different reflectance bands within a scene. Therefore, data from an adjacent 
wavelength band could be used to adjust the anomalous scan-line reflectance values to correspond to adjacent "normal" reflectance. Data within areas on both sides of the anomalous scan lines were compared by linear least squares analysis to corresponding data in adjacent wavelength bands to determine which adjacent band most correlated with the band having the anomalous scan lines and to determine the linear reflectance relation between the two bands. The most linear relation was used to adjust the adjacent band data to the band data having the anomalous scan lines and the resulting "synthesized" data replaced the anomalous scan lines. The results were visually inspected to ensure the quality of the adjustment by digitally stretching the "synthesized" image area to determine if there were residual brightness discontinuities. The process worked very well.

\section{Countrywide Image-to-Image Reflectance Calibration}

No image calibration can completely correct large scene-to-scene differences in solar incidence angle, such as exists within our Landsat scene collection ( $38^{\circ}$ to $65^{\circ}$; Table 2$)$. Therefore, an image-to-image least-squares adjustment was implemented to adjust the band reflectance within a scene to the corresponding band reflectance of an adjacent scene. This process required a scene or set of scenes to serve as the standard lighting condition. The scenes within Path 155 were selected as the standard set of scenes for normalization of all other scenes for the country mosaics. The scenes within Path 155 were all acquired on the same day close to summer solstice when the solar elevation angle was relatively high and therefore surface reflectance was the closest to surface normal reflectance that can be obtained from the Sun-synchronous Landsat satellite. This Path also covers most of the latitude range within Afghanistan and it is located in the middle of the country (Figure 1). Examination of the reflectance data within regions of overlap between each pair of scenes within Path 155 showed the reflectance values to be very consistent scene to scene.

In order to derive least squares relations between two scenes it is necessary to remove from consideration surface areas that had changed between the two scene acquisition dates. These changes were generally vegetation, snow, ice, and clouds. Therefore, the initial step in the adjustment process was to construct image masks for clouds, snow, and ice. The least-squares algorithm used NDVI values to determine and exclude vegetation and used the masks to exclude snow, ice, and clouds. The algorithm determined the region of overlap between two scenes using their UTM coordinates, masked out the vegetation, snow, ice, and clouds, and then preformed a linear least-squares determination for each Landsat band that related a band's reflectance to the band reflectance of the standard scene. The least-squares algorithm produced a two-dimensional plot of the pixel-to-pixel correspondence in reflectance for each band; these plots were examined and points were edited to exclude anomalies. If segments of the plotted data were not linear, the band data within the nonlinear range were examined to determine the reason and make adjustments. Nonlinearity was usually caused by incomplete removal of surfaces that had changed between the two scenes. The set of band linear equations were then applied to the scene to adjust its band reflectance values to that of the standard scene.

The process started with scenes adjacent to Path 155 and moved east and west, using the adjusted scenes as the standards for scenes further east and west. After each scene was adjusted, the adjusted scene was mosaicked with adjacent "standard" scenes and the overlap borders were examined by applying a very hard digital stretch to each 400-pixel segment along the border seam. If a discontinuity was detected, the least squares data and equation were re-examined, revised, and re-applied until there were no visible brightness discontinuities along overlap borders. The linear 
adjustment to the scenes not only compensated for different solar illuminations, but also compensated for incomplete removal of atmospheric scattering between scenes.

\section{Noise Correction of Panchromatic Image Data}

The Landsat panchromatic image data at $14.25-\mathrm{m}$ spatial resolution provide more morphologic details than the 28.5-m Landsat multispectral bands. However, inspection of the panchromatic images revealed a high density of random noise (Figure 2a), which was introduced into the raw data by the modulation transfer function applied by the EROS Data Center during their ephemerid rectification of the scenes. The random nature and variable brightness levels of the noise made its removal by conventional digital filters impossible without serious degradation of the true signal information. However, the adaptive sigma filter designed by Eliason and McEwen (1990) removed most of the noise with the least effect on the true signal data. This filter was applied to each panchromatic image using a filter dimension of $3 \times 3$ and a 2.7 standard deviation tolerance. This filter did reduce the sharpness of the image somewhat, so a subsequent $5 \times 5$ highpass filter was applied using a 95 percent addback of the original image data (also known as an edge enhancement filter). The result of this process on the panchromatic data is demonstrated by Figure $2 b$.

\section{Resolution Enhancement of the 28.5-m Reflectance Image Data}

The 14.25-m panchromatic images contain more morphologic information on bedding, faults, surface texture, cultural features, and small streams than the 28.5-m multispectral image data. In order to make use of this higher resolution texture and the spectral information contained in the multispectral data, a resolution enhancement algorithm was applied to both data sets to produce a multispectral dataset with $14.25-\mathrm{m}$ resolution. There have been many different algorithms developed over the past decade for resolution enhancement, for each of which the earliest and latest references is provided: color normalized (Hallada and Cox, 1983), intensity-huesaturation merge (Haydn et al., 1982; Chavez et al., 1991), principal component analysis (Chavez et al., 1991), wavelet decomposition (Yocky, 1996; Gonzalez-Audicana, 2004), modulation transfer functions (Goforth, 1998; Alazzi et al., 2006), pixel unmixing (Zhukov et al., 1999), and SPARKLE (unpublished ERIM proprietary algorithm). Vrabel (1996; 2000) statistically examined many of these techniques to determine which technique provided the most improvement in ground sample distance while retaining most of the original spectral information. These studies indicated that the color normalized and the SPARKLE approach performed the best, although I have found through experimentation that the color normalized approach does not retain spectral fidelity and therefore the SPARKLE algorithm was implemented on our Landsat multispectral and "corrected" panchromatic image data.

The basic concept of the SPARKLE algorithm is that a higher resolution panchromatic image can be filtered to duplicate the effect of the modulation transfer function of the lower resolution multispectral sensor. Once accomplished the ratio of the original panchromatic image to the filtered panchromatic image is multiplied by each scene's multispectral bands and the highfrequency information in the panchromatic image will be transferred to the multispectral bands with no change in the relative spectral relations for any particular pixel. I have found that is true except along abrupt vegetation borders and I, therefore, test each pixel's result to determine if the reflectance relations change by more than one percent from the original relations and, if it did, the original pixel values are retained in the final product. An example of the SPARKLE resolution enhancement is shown for a small area in Afghanistan in Figure 3. 


\section{Reprojection of Landsat Scenes along UTM Zone Borders}

Along the borders of the UTM zones within Afghanistan the Landsat scenes were orthorectified to the UTM zone containing the majority of the scene. Thus, scene projections change from zone 42 in the north to zone 43 in the south along the boundary of those two zones, as well as along the zone $42-43$ boundary. Therefore, scenes straddling the zone boundaries had to be reprojected into the other zone to make our UTM image mosaics. Investigation of different methods (RST, Triangulation, Polynomial) and degrees of map reprojection showed that the method that retained the most control was a second-order polynomial transformation using an $\mathrm{x}$ and y control-point grid of 90 x 90 (i.e., 8100 control points) for the $28.5-\mathrm{m}$ scenes. The enhanced $14.25-\mathrm{m}$ scenes required a 180 x 180 control-point grid.

\section{Mosaicking of Landsat Scenes into Map Quadrangles}

For map production purposes in the Afghanistan project, the country was divided into $1^{\circ} \mathrm{x}$ $2^{\circ}$ tiles and each tile is labeled by the latitude and longitude values of its lower left corner (Figure 4). Thus, tile 3468 has a lower left corner at $34^{\circ} \mathrm{N}$ of latitude and $68^{\circ} \mathrm{E}$ of longitude. Some of the calibrated Landsat scenes required some manual trimming before mosaicking in order to minimize cloud, snow, and ice cover, and to avoid areas that had otherwise changed within the region of overlap of two scenes. In addition, some degree of feathering was applied during the mosaicking process, especially in desert areas that have very low contrast. Feathering is an image processing procedure whereby the digital values of two images are proportionally blended (from 0 to 100 percent) over a specified distance perpendicular to their overlap border. As the process proceeds away from the border, the proportion used of underlying image decreases from 100 percent and that of the overlying image increases to 100 percent. To maintain the original 50-m positional accuracy of the image data, each map tile was constructed separately only using the Landsat scenes (or portions of scenes) that covered the map tile. Once completed, each tile was trimmed to provide 100 meter outside border to provide overlap with all adjacent map tiles. Each band in the tile was then converted to an embedded geotiff with a world file and all of the band tiffs and world files for a map tile were compressed into a single digital file whose file name corresponded to the map tile number.

All of the 28.5-m and 14.25-m map tiles containing the calibrated nonthermal Landsat bands for Afghanistan can be downloaded from http://gisdata.usgs.net/website/afghan.

\section{References Cited}

Alazzi, B., Alparone, L., Baronti, S., Garzelli, A., and Selva, M., 2006, MTF-tailored multiscale fusion of high-resolution MS and pan imagery. Photogrammetric Engineering and Remote Sensing, v. 72, p. 591-596.

Chavez, P. S., Sides, S. C., and Anderson, J. A., 1991, Comparison of three different methods to merge multiresolution and multispectral data: Landsat TM and SPOT panchromatic. Photogrammetric Engineering and Remote Sensing, v. 57, p. 295-303.

Eliason, E. M. and McEwen, A. S., 1990, Adaptive box filters for removal of random noise from digital images. Photogrammetric Engineering and Remote Sensing, v. 56, p. 453-458. 
Goforth, M. A., 1998, Multispectral image sharpening with multiresolution analysis and the MTF. Proceedings of the SPIE Conference on Algorithms for Multispectral and Hyperspectral Imagery IV, SPIE Volume 3372, (Shen, S. S. and Descour, M. R., Eds.), p. 123-131.

Gonzalez-Audicana, M., Saleta, J. L., Catalan, R. G., and Garcia, R., 2004, Fusion of multispectral and panchromatic images using improved HIS and PCA mergers based on wavelet decomposition. IEEE Transactions on Geoscience and Remote Sensing, v. 42, p. 1291-1299.

Hallada, W. A., and Cox, S., 1983, Image sharpening for mixed spatial and spectral resolution satellite systems. Proceedings Seventh International Symposium on Remote Sensing of Environment, Environmental Research Institute of Michigan, Ann Arbor, p. 1023-1032.

Haydn, R., Dalke, G. W., Henkel, J., and Bare, J. E., 1982, Application of the HIS color transform to the processing of multisensor data and image enhancement. Proceedings International Symposium on Remote Sensing of Environment, First Thematic Conference: Remote Sensing of Arid and Semi-arid Lands, Environmental Research Institute of Michigan, Ann Arbor, p. 599616.

Hunt, G., R., and Salisbury, J. W., 1970, Visible and near-infrared spectra of minerals and rocks: I. Silicate minerals. Modern Geology, v. 1, p. 283-300.

Hunt, G. R., and Salisbury, J. W., 1971, Visible and near-infrared spectra of minerals and rocks: II. Carbonates. Modern Geology, v. 2, p. 23-30.

Hunt, G. R., Salisbury, J. W., and Lenoff, C. J., 1971a, Visible and near-infrared spectra of minerals and rocks: III. Oxides and hydroxides. Modern Geology, v. 2, p. 195-205.

Hunt, G. R., Salisbury, J. W., and Lenoff, C. J., 1971b, Visible and near-infrared spectra of minerals and rocks: IV. Sulphides and sulphates. Modern Geology, v. 3, p. 1-14.

Kalluri, S., Grant, D., Tucker, C., Policelli, F., Dykstra, J., and Bearden, P., 2000,, NASA creates global archive of ortho-rectified Landsat data. EOS, Transactions, American Geophysical Union, v. 81 , no. 50 , p. $609,617-618$.

Matthew, M.W., Adler-Golden, S. M., Berk, A., Felde, G., Anderson, G. P., Gorodetzky, D., Paswaters, S., and Shippert, M., 2003, Atmospheric correction of spectral imagery: evaluation of the FLAASH algorithm with AVIRIS data. SPIE Proceeding, (Shen, S. S., and Lewis, P. E., Eds.), Algorithms and Technologies for Multispectral, Hyperspectral, and Ultraspectral Imagery IX, v. 5093. pp. 474-482.

RSI, 2004, FLAASH User's Guide, Version 4.1, 80 p.

Vrabel, J., 1996, Multispectral imagery band sharpening study, Photogrammetric Engineering and Remote Sensing, v. 62, p. 1075-1083.

Vrabel, J., 2000, Multispectral imagery advanced band sharpening study. Photogrammetric Engineering and Remote Sensing, v. 66, p. 73-79. 
Yocky, D. A., 1996, Multiresolution wavelet decomposition image merger of Landsat Thematic Mapper and SPOT panchromatic data. Photogrammetric Engineering and Remote Sensing, v. 62, p. 1067-1074.

Zhukov, B., Oertel, D., Lanzl, F., and Reinhackel, G., 1999, Unmixing-based multisensor multiresolution image fusion. IEEE Transactions on Geosceince and Remote Sensing, v. 37, p.1212-1226. 


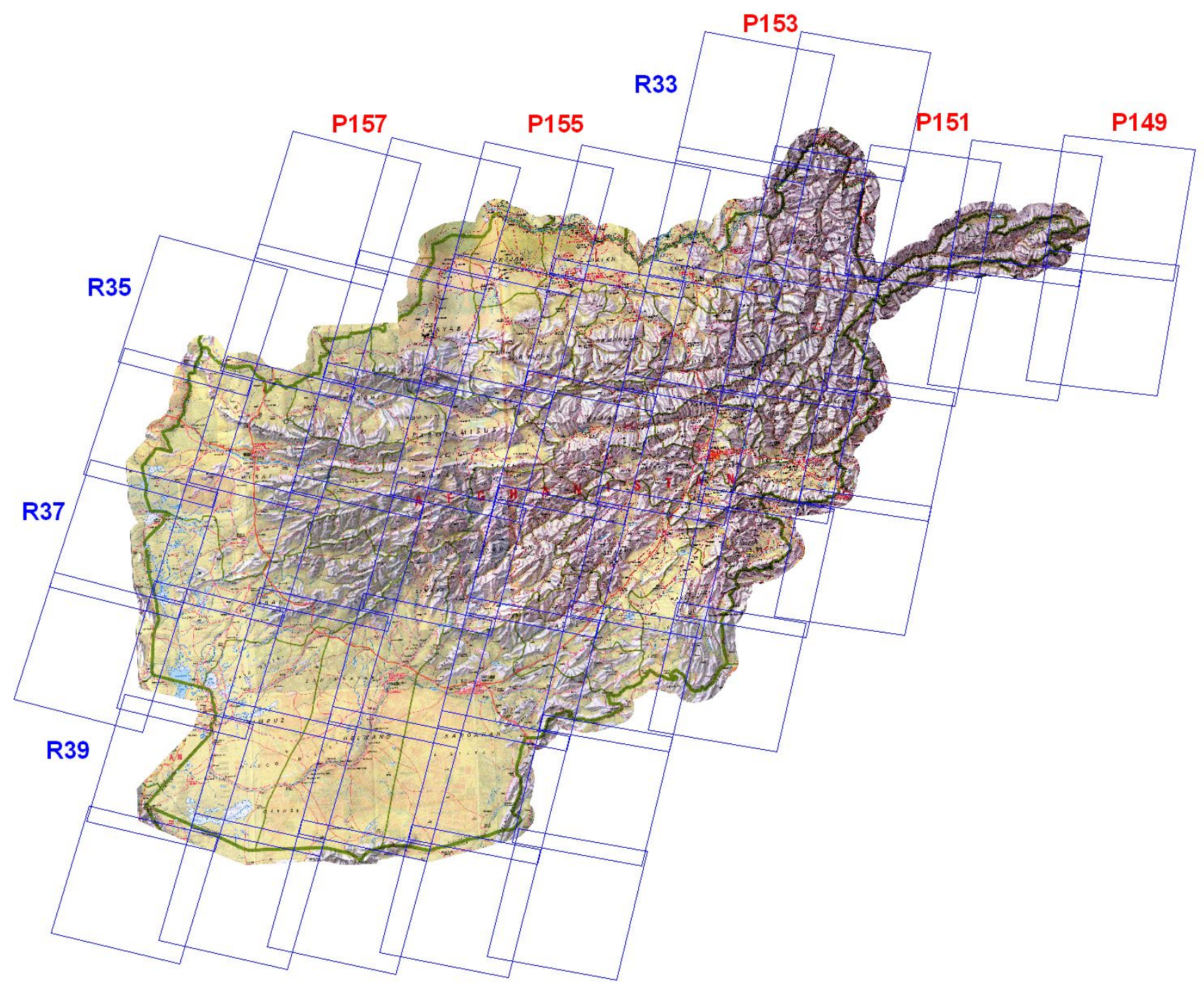

Figure 1. Landsat ETM+ scene outlines superposed on a map of Afghanistan. " $P$ " indicates Path (red) and " $R$ " indicates Row (blue). 

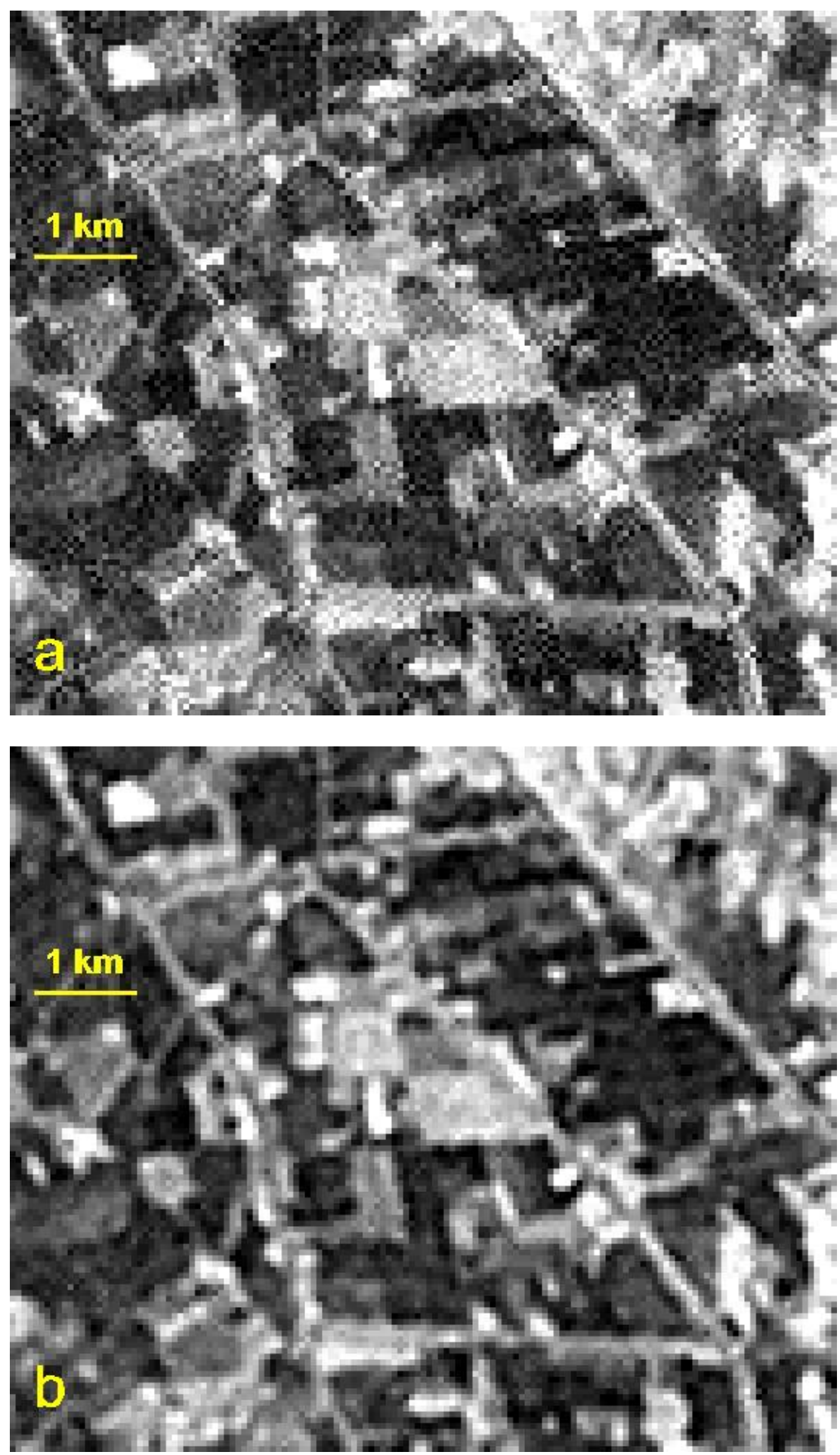

Figure 2. Panchromatic image of an agricultural area in southern Afghanistan showing (a) dense, random noise present in the original orthorectified Landsat panchromatic images obtained from the EROS Data Center archive, and (b) the corresponding image after application of the adaptive sigma filter and an edge enhancement filter. 


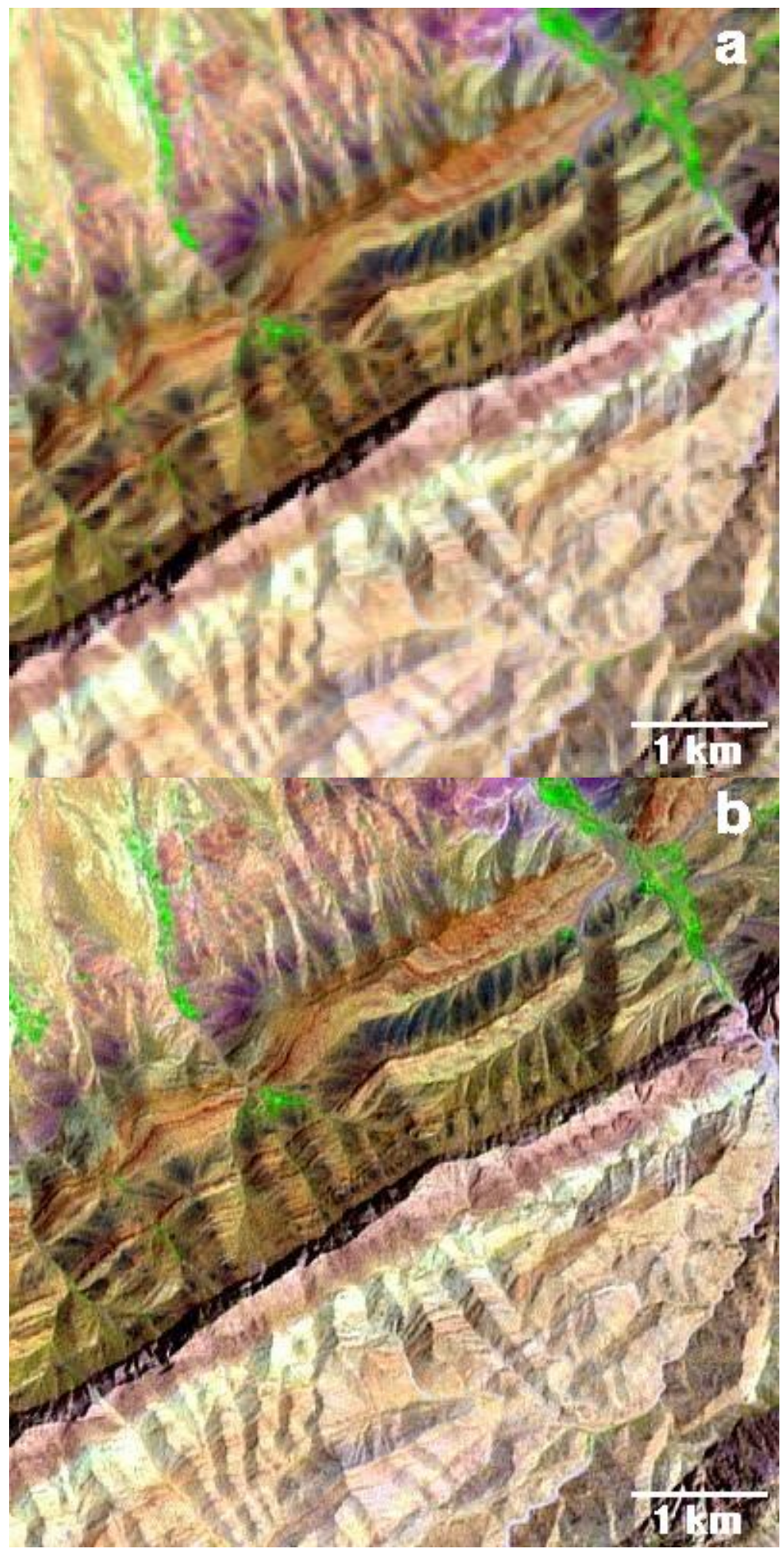

Figure 3. Landsat false-color image at (a) original 28.5-m resolution and (b) enhanced 14.25-m resolution. Landsat bands 7, 4, and 1 are displayed as red, green, and blue, respectively. 


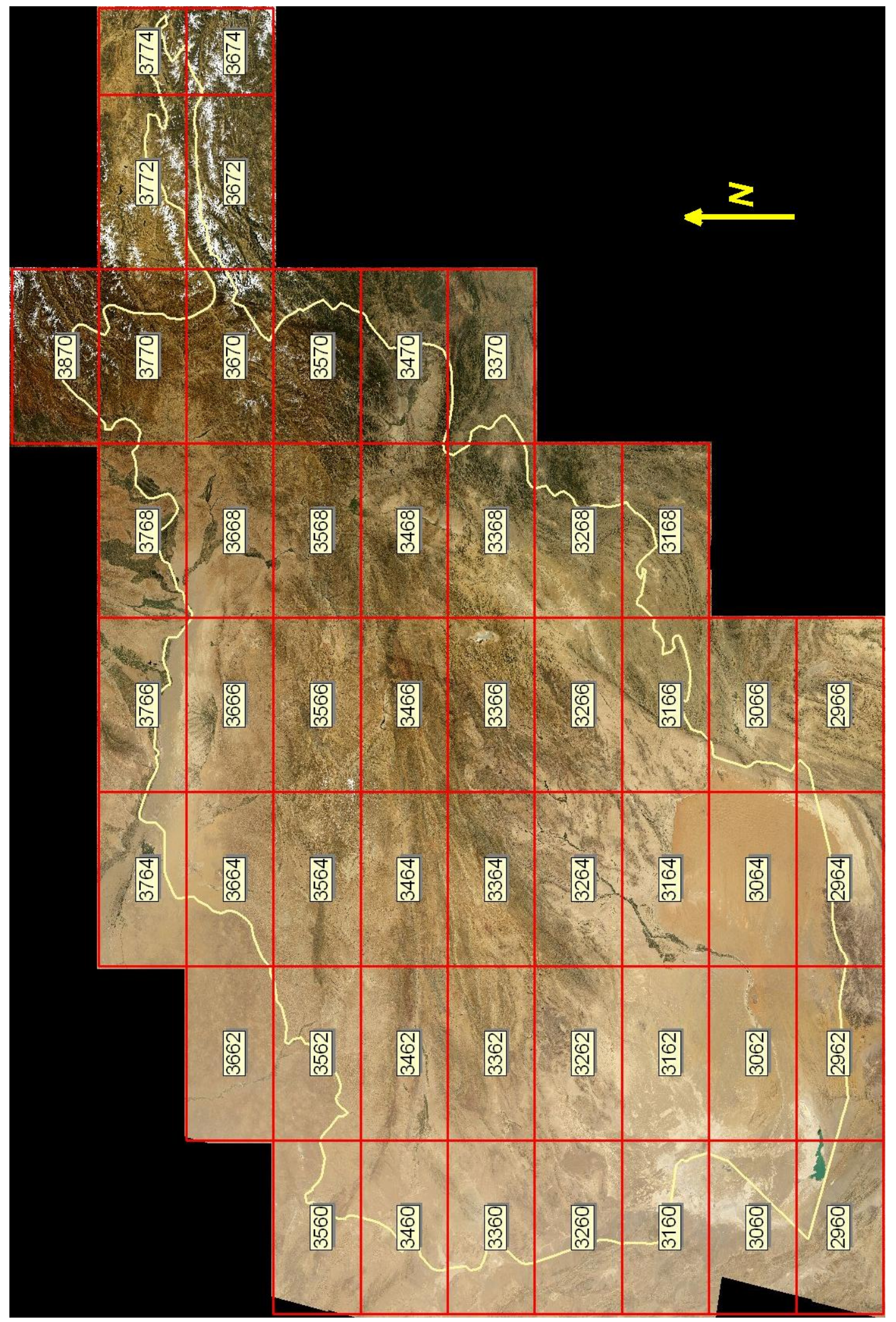

Figure 4. Map tile scheme for the Afghanistan project (on a natural-color image base) with each $1^{\circ} \times 2^{\circ}$ map quadrangle designated by its lower left corner latitude and longitude. 
Table 1. Characteristics of Landsat ETM+ Image Data.

\begin{tabular}{cccc}
\hline ETM+ Band Number & $\begin{array}{c}\text { Wavelength Range } \\
(\boldsymbol{\mu} \mathbf{m})\end{array}$ & Wavelength Region & Resolution (m) \\
\hline 1 & $0.45-0.52$ & Blue & 28.50 \\
2 & $0.52-0.60$ & Green & 28.50 \\
3 & $0.63-0.69$ & Red & 28.50 \\
4 & $0.76-0.90$ & Near-Infrared & 28.50 \\
5 & $1.55-1.75$ & Shortwave Infrared & 28.50 \\
6H (high gain) & $10.40-12.50$ & Thermal Infrared & 57.00 \\
6L (low gain) & $10.40-12.50$ & Thermal Infrared & 57.00 \\
7 & $2.08-2.35$ & Shortwave Infrared & 28.50 \\
8 & $0.52-0.90$ & Visible Panchromatic & 14.25 \\
\hline
\end{tabular}


Table 2. Landsat ETM+ Image Data Used in the Countrywide Image Mosaic

\begin{tabular}{|c|c|c|c|c|}
\hline Landsat Scene ID & $\begin{array}{c}\text { Acquisition Time } \\
\text { (GMT) }\end{array}$ & $\begin{array}{c}\text { Solar Elevation } \\
\text { Angle (degrees) }\end{array}$ & Center Latitude & Center Longitude \\
\hline ELP149R034_7T20010930 & $5: 23: 22$ & 45.18 & $37.4721 \mathrm{~N}$ & $75.5768 \mathrm{E}$ \\
\hline ELP149R035_7T20010930 & $5: 23: 46$ & 46.28 & $36.0378 \mathrm{~N}$ & $75.1547 \mathrm{E}$ \\
\hline ELP150R034_7T19990815 & $5: 34: 02$ & 58.69 & $37.4797 \mathrm{~N}$ & $74.0922 \mathrm{E}$ \\
\hline ELP150R035_7T19990916 & $5: 34: 24$ & 51.28 & $36.0485 \mathrm{~N}$ & $73.6861 \mathrm{E}$ \\
\hline ELP151R034_7T20010928 & $5: 35: 44$ & 45.83 & $37.4723 \mathrm{~N}$ & $72.4802 \mathrm{E}$ \\
\hline ELP151R035_7T20001027 & $5: 38: 24$ & 37.77 & $36.0463 \mathrm{~N}$ & $72.1177 \mathrm{E}$ \\
\hline ELP151R036_7T20010928 & $5: 36: 34$ & 47.96 & $34.6110 \mathrm{~N}$ & $71.6543 \mathrm{E}$ \\
\hline ELP151R037_7T20001011 & $5: 38: 54$ & 45.14 & $33.1761 \mathrm{~N}$ & $71.2544 \mathrm{E}$ \\
\hline ELP152R033_7T20000916 & $5: 43: 49$ & 48.72 & $38.9082 \mathrm{~N}$ & $71.4102 \mathrm{E}$ \\
\hline ELP152R034_7T20010802 & $5: 42: 40$ & 60.52 & $37.4782 \mathrm{~N}$ & $70.9474 \mathrm{E}$ \\
\hline ELP152R035_7T20010802 & 5:43:04 & 61.11 & $36.0439 \mathrm{~N}$ & $70.5284 \mathrm{E}$ \\
\hline ELP152R036_7T20011005 & $5: 42: 36$ & 45.77 & $34.6130 \mathrm{~N}$ & $70.1216 \mathrm{E}$ \\
\hline ELP152R037_7T20001018 & $5: 44: 55$ & 42.94 & $33.1784 \mathrm{~N}$ & $69.7880 \mathrm{E}$ \\
\hline ELP152R038_7T20001018 & $5: 45: 28$ & 44.09 & $31.7436 \mathrm{~N}$ & $69.3987 \mathrm{E}$ \\
\hline ELP153R033_7T20010708 & $5: 48: 42$ & 63.58 & $38.9110 \mathrm{~N}$ & $69.8427 \mathrm{E}$ \\
\hline ELP153R034_7T20010708 & $5: 49: 05$ & 64.07 & $37.4774 \mathrm{~N}$ & $69.4083 \mathrm{E}$ \\
\hline ELP153R035_7T20010708 & $5: 49: 28$ & 64.49 & $36.0482 \mathrm{~N}$ & $68.9902 \mathrm{E}$ \\
\hline ELP153R036_7T20000822 & $5: 51: 32$ & 58.19 & $34.6113 \mathrm{~N}$ & $68.5849 \mathrm{E}$ \\
\hline ELP153R037_7T20001025 & $5: 51: 10$ & 40.76 & $33.1808 \mathrm{~N}$ & $68.2271 \mathrm{E}$ \\
\hline ELP153R038_7T20001009 & $5: 51: 41$ & 46.87 & $31.7457 \mathrm{~N}$ & $67.7766 \mathrm{E}$ \\
\hline ELP153R039_7T20001009 & $5: 52: 04$ & 47.96 & $30.3087 \mathrm{~N}$ & $67.3968 \mathrm{E}$ \\
\hline ELP153R040_7T20001025 & $5: 52: 23$ & 44.24 & $28.8720 \mathrm{~N}$ & $67.0830 \mathrm{E}$ \\
\hline ELP154R034_7T20010731 & $5: 55: 03$ & 60.87 & $37.4771 \mathrm{~N}$ & $67.8560 \mathrm{E}$ \\
\hline ELP154R035_7T20010629 & $5: 55: 48$ & 65.26 & $36.0489 \mathrm{~N}$ & $67.4779 \mathrm{E}$ \\
\hline ELP154R036_7T20010629 & $5: 56: 00$ & 65.59 & $34.6182 \mathrm{~N}$ & $67.0698 \mathrm{E}$ \\
\hline ELP154R037_7T20000525 & $5: 59: 03$ & 66.41 & $33.1810 \mathrm{~N}$ & $66.6676 \mathrm{E}$ \\
\hline ELP154R038_7T20010629 & $5: 56: 50$ & 66.00 & $31.7496 \mathrm{~N}$ & $66.2818 \mathrm{E}$ \\
\hline ELP154R039_7T20010629 & $5: 57: 14$ & 66.08 & $30.3110 \mathrm{~N}$ & $65.9008 \mathrm{E}$ \\
\hline ELP154R040_7T20010629 & $5: 57: 38$ & 66.07 & $28.8760 \mathrm{~N}$ & $65.5294 \mathrm{E}$ \\
\hline ELP155R034_7T20010503 & 6:02:08 & 60.59 & $37.4830 \mathrm{~N}$ & $66.3074 \mathrm{E}$ \\
\hline ELP155R035_7T20010503 & $6: 02: 33$ & 61.32 & $36.0541 \mathrm{~N}$ & $65.8877 \mathrm{E}$ \\
\hline ELP155R036_7T20010503 & $6: 02: 58$ & 62.01 & $34.6160 \mathrm{~N}$ & $63.9870 \mathrm{E}$ \\
\hline ELP155R037_7T20010503 & 6:03:21 & 62.63 & $33.1878 \mathrm{~N}$ & $65.0803 \mathrm{E}$ \\
\hline
\end{tabular}




\begin{tabular}{ccccc}
\hline \multicolumn{1}{c}{ Landsat Scene ID } & $\begin{array}{c}\text { Acquisition Time } \\
\text { (GMT) }\end{array}$ & $\begin{array}{c}\text { Solar Elevation } \\
\text { Angle (degrees) }\end{array}$ & Center Latitude & Center Longitude \\
\hline ELP155R038_7T20010503 & $6: 03: 45$ & 63.24 & $31.7511 \mathrm{~N}$ & $64.6912 \mathrm{E}$ \\
ELP155R039_7T20010503 & $6: 04: 08$ & 63.70 & $30.3176 \mathrm{~N}$ & $64.3117 \mathrm{E}$ \\
ELP155R040_7T20010503 & $6: 04: 33$ & 64.14 & $28.8790 \mathrm{~N}$ & $63.9390 \mathrm{E}$ \\
ELP156R034_7T20010627 & $6: 07: 35$ & 65.00 & $37.4809 \mathrm{~N}$ & $64.8165 \mathrm{E}$ \\
ELP156R035_7T20010627 & $6: 07: 58$ & 65.40 & $36.0471 \mathrm{~N}$ & $64.3954 \mathrm{E}$ \\
ELP156R036_7T20010627 & $6: 08: 23$ & 65.72 & $34.6160 \mathrm{~N}$ & $63.9870 \mathrm{E}$ \\
ELP156R037_7T20010627 & $6: 08: 47$ & 65.96 & $33.1843 \mathrm{~N}$ & $63.5895 \mathrm{E}$ \\
ELP156R038_7T20010510 & $6: 09: 50$ & 64.52 & $31.7493 \mathrm{~N}$ & $63.1516 \mathrm{E}$ \\
ELP156R039_7T20010510 & $6: 10: 14$ & 64.94 & $30.3158 \mathrm{~N}$ & $62.7724 \mathrm{E}$ \\
ELP156R040_7T20010510 & $6: 10: 38$ & 65.29 & $28.8768 \mathrm{~N}$ & $62.4000 \mathrm{E}$ \\
ELP157R034_7T20010517 & $6: 14: 18$ & 63.44 & $37.4821 \mathrm{~N}$ & $63.2390 \mathrm{E}$ \\
ELP157R035_7T20010517 & $6: 14: 42$ & 64.06 & $36.0532 \mathrm{~N}$ & $62.8194 \mathrm{E}$ \\
ELP157R036_7T20010517 & $6: 15: 05$ & 64.62 & $34.6180 \mathrm{~N}$ & $62.4094 \mathrm{E}$ \\
ELP157R037_7T20010517 & $6: 15: 30$ & 65.11 & $33.1864 \mathrm{~N}$ & $62.0113 \mathrm{E}$ \\
ELP157R038_7T20010720 & $6: 15: 21$ & 64.12 & $31.7445 \mathrm{~N}$ & $61.5978 \mathrm{E}$ \\
ELP157R039_7T20000919 & $6: 16: 55$ & 53.77 & $30.3107 \mathrm{~N}$ & $61.2710 \mathrm{E}$ \\
ELP157R040_7T20010704 & $6: 16: 12$ & 65.74 & $28.8766 \mathrm{~N}$ & $60.8759 \mathrm{E}$ \\
ELP158R035_7T20010711 & $6: 20: 23$ & 64.18 & $36.0457 \mathrm{~N}$ & $61.2592 \mathrm{E}$ \\
ELP158R036_7T20000708 & $6: 22: 59$ & 65.23 & $34.6103 \mathrm{~N}$ & $60.8681 \mathrm{E}$ \\
ELP158R037_7T20010625 & $6: 21: 10$ & 66.09 & $33.1829 \mathrm{~N}$ & $60.4928 \mathrm{E}$ \\
ELP158R038_7T20010625 & $6: 21: 35$ & 66.25 & $31.7459 \mathrm{~N}$ & $60.1046 \mathrm{E}$ \\
\hline
\end{tabular}

